\title{
Social Development through Storytelling at Heritage Sites and Museums
}

Souzan Ibrahim

\begin{abstract}
Storytelling has very old routes and history which dates back to the ancient times. Before the inventing of writing, the oral storytelling was very important for social experiences and edutainment. Recently, storytelling can be used in museums to improve the writing skills, literacy and listening skills as it offers an opportunity of learning without teaching. In order to create a story, data about collections should be correctly gathered to organize them and form a story. Then, the last step of choosing the medium of narration is needed which vary according to many factors. The digital mediums of telling stories can be widely used in different fields. In the field of heritage, digital storytelling can work on the improvement of education, cultural mediation and tourism. Unfortunately, digital storytelling is facing a range of challenges like the cost and technical problems. In order to form a good story, EMOTIVE association has set a number of guidelines addressing the plot as a core of any story.
\end{abstract}

\section{Keywords:}

Storytelling, Digital Storytelling, Museums, Cultural Heritage, Story.

\section{History of Storytelling}

In order to use storytelling as an effective method in museums, its history should be studied. The beginning of using storytelling in museums was in 1930 at the Deutsches museum while working on an interactive exhibition which gives the visitors the opportunity to learn in a "hands- on" learning experience". The museum was founded by Oskar von Miller in 1903. The museum's mission was that "the exhibitions should give an encyclopaedic overview of all areas of technology and exact sciences to demonstrate the historical interaction of science, technology and industry and to illustrate the most important stages of development by exhibiting eminent and characteristic masterpieces" ${ }^{2}$. The Director General of National Council on Science Museums stated that "rethinking museums would result in a plan for a paradigm shift in the concept of museums, the kind of shift that the Deutsches Museum demonstrated in the 1930s inviting visitors' participation in working exhibits". Storytelling continued to be developed in museums. In 2012 an interview was conducted by the AAM press with Andy Goodman who is an author, a consultant and a storyteller. The interview was entitled "A Conversation with Andy Goodman" discussing the development of storytelling in museums. One of the points that he stated in his interview is that the museums are like a journey in which the visitor can travel through a story which take them to a new place and time. Today, storytelling aims to enhance visitors' personal experience and engage them with the history of the objects. Also, storytelling facilitated the process of telling the history of museums along with their collections ${ }^{3}$.

\section{WhyStorytelling?}

Storytelling is considered one of the oldest means of communication which has a powerful ability of improving imagination and gaining new experiences and perspectives. Stories are a vital means of supporting and improving many social skills in the society for all ages and especially children. The increasing and incessant importance and effect of storytelling is proved by its existence into our life. We witness this existence in our real life-time stories or the stories that we got through films, fiction and drama. Storytelling has a great impact on children as it is a very important learning tool for them where they can learn and enjoy. Stories

\footnotetext{
'Hayley Trinkoff, "Storytelling in Art Museums." (Master diss., Seton Hall University, 2015), 8.

${ }^{2}$ Wolf Peter Fehlhammer and Wilhelm Fuessl, "The Deutsches Museum: Idea, Realization, and Objectives," Journal of the Technology and Culture 41, no. 3 (2000): 517-520. https://muse.jhu.edu/article/33555/summary

${ }^{3}$ Hayley Trinkoff, "Storytelling in Art Museums." (Master diss., Seton Hall University, 2015), 8.
} 
can easily reach children when approaching some critical or personal issues like those related to family. Sharing or reading the good literature with children is considered a useful educational tool. However, storytelling still has a different approach of improving the social skills and providing the listener with edutainment atmosphere ${ }^{4}$.

In addition, storytelling can present the facts with special flavors which in turn increase the desire of learning, educating and knowing. Some museums or heritage sites are using storytelling method to help visitors travel over different times and places by visualizing and living with the history through a story. Narrating relevant stories to museums' collections can help visitors to discover the tangible and intangible cultures using the stories about these collections.

To communicate with museums' visitors through a dialogue become one of the important functions of museums to educate and improve communities' social skills. Storytelling is considered one of the golden keys of communication in museums and heritage sites. In order to tell a story in museums, three main mechanisms should exist. The first mechanism is the collecting of the data; the second is organizing these data to form a story while the third is choosing the medium of telling the story ${ }^{5}$. Before explaining these three mechanisms of telling a story, the author would first prefer to reference storytelling definition and some of its benefits.

\section{Benefits of Storytelling Improves listening skills}

Reading aloud has the power of improving listening skills for children; however, many people do not believe in the power of the oral storytelling. Storytelling gives the opportunity for children to engage with the story and the teller which in turn will help them to develop strong listening skills. The process of telling a story helps children in visualizing characters and actions without the help of real images. This visualization helps children to create mental images with the spoken word of the story.

\section{Develops literacy Rate}

Literacy is not only about reading, but also it includes language, vocabulary and writing skills. Children's linguistic skills can be improved through the frequent chances of telling stories. Listening to a story as well as telling it can help children to recognize the sequence and structure of the stories. Using these benefits can offer children the link to improve reading and writing skills.

\section{Learning without teaching}

Telling children what they should or should not do by giving them instructions is important, but not always effective. Storytelling has this power of learning without teaching and engaging children with their surrounded world by reading, watching or listening to a story. Stories are different and have many levels where we can choose which level is suitable for which age. Storytelling is consolidating the natural way through which we can learn about things. Telling stories for children can educate them many ethics and roles in an indirect way of communication ${ }^{6}$.

\section{The Process of Storytelling}

In order to tell a story, three main steps should be considered. These steps are as follows:

\section{Data Collecting}

Museums and the other heritage sites are facing some problems regarding collections registration. In some cases the full records of the collections do not exist, while in other cases some information is misleading. Therefore, a detailed research should be done before starting to write a story about museums' collections, because they should be true stories. The responsibility of getting the authentic information is a shared responsibility between museums directors, curators and experts.

\footnotetext{
${ }^{4}$ Steve Killick and Maria Boffey, Building relationships through storytelling (England: Fostering Network Wales press, 2012), 2.

${ }^{5}$ Fort Museum, Archaeological Survey of India. Report of Telling Stories with Museum Objects: Reflection on Interpretation, (Chennai: Fort St. George Printer).

${ }^{6}$ Steve Killick and Maria Boffey, Building relationships through storytelling (England: Fostering Network Wales press, 2012), 5.
} 


\section{Converting Data into Stories}

The second step comes here after collecting the authentic and the required data. Organizing and framing this data in a way to form short, long or a bunch of stories is essential. Museums are the places where visitors can get the complete version of a story, while magazines, newspapers and other advertising tools provide the incomplete stories. These advertising mediums tell their followers that they can find the complete stories if they visit museums personally. In other cases, museums leave some parts of the story to be completed by the visitors as a kind of engagement.

\section{Mediums of Storytelling}

Choosing the mediums will affect the atmosphere of the story and the level of engagement. It is also affected by the type of information, the age of the receiver and the place of telling the story. Storytelling mediums are several and we are going to mention some of them as follows:

\section{- Narration through Pictures}

Picture narrations do not need words in order to tell a story. It depends only on analyzing the available pictures to know the story. This way of not using a single word can help the uneducated as well as children to understand the content easily.

\section{- Literature}

Museums and many other cultural institutions are using printed means of marketing and advertising. Brochures, leaflets and guidebooks are among this literature which can carry many stories to be more popularized among the visitors.

\section{- Guides Existence}

Guides as human beings are telling stories in museums which can achieve a good level of engagement with the visitors; however they might cause some disturbance for the other visitors with their laud voices.

\section{- Theatre Shows}

Museums theaters are representing the live place in which visitors can see history alive by trained artists who tell stories. With the arrival of the new technology and museums digital age, some other mediums for telling stories were considered in museums and heritage sites. Museums can now tell stories about objects by using many diverse and accessible mediums like dioramas, audio, video, QR code, 3D shows and augmented reality. These new technologies opened new ways of engaging the visitors within an easy access, where museums can go to the doorsteps of the visitors who will not go to museums $^{7}$

\section{Digital Storytelling}

Using digital storytelling in museums and heritage sites has become vital for many reasons like reaching a wider community and merging tourism with culture. The adoption of Interactive Multimedia Digital Storytelling is a distinguished tool for engaging the audience. "Multimedia" refers to the use of texts and images along with audio, video and graphics. "Digital" means using the modern technological devices like tablets and smart phones. "Storytelling" is about providing the users with a story not just the information to deliver the cultural message ${ }^{8}$

The development of the social networking sites and the modern technologies has opened new ways and techniques of telling stories. The term of digital storytelling has appeared since the 1990s and developed later to offer new ways of narratives. Digital storytelling can be used in different fields. However, the author will focus on the use of digital storytelling on cultural heritage. The field of cultural heritage has three main axes which can be improved by using digital storytelling. These axes are education, cultural mediation and tourism.

\section{Education}

In order to create meaning, many professionals are using storytelling in the learning process. The use of multimedia can help

\footnotetext{
${ }^{7}$ Fort Museum, Archaeological Survey of India. Report of Telling Stories with Museum Objects: Reflection on Interpretation, (Chennai: Fort St. George Printer)

${ }^{8}$ Paolo Paolini and Nicoletta Di Blas, Storytelling for cultural heritage (Switzerland: In Innovative technologies in urban mapping, 2014), 33-45, https:// link.springer.com/chapter/10.1007/978-3-319-03798-1_4
} 
students or visitors to understand the difficult ingredients and ideas. In addition, it can add an opportunity of gaining a wide range of information. Using digital storytelling in museums and heritage sites can create a global space for participation and communication while giving the opportunity for the visitors to form their own stories and share it with the others.

\section{Cultural Mediation}

Among the different means of engaging visitors in museums and heritage sites, digital storytelling can effectively engage them and attract new audience. By having the nature of edutainment, digital storytelling coped with the new trends in museums which aimed to provide an interactive experience to visitors and hence engaging them with the surrounding communities.

\section{Tourism}

The growing competition between tourism destinations and suppliers requires more dynamic and innovative process. Cultural heritage destinations are among the favorite paths for tourists. The digital age offered a great chance for these tourists to gain more experiences from each other by exchanging travel stories for example ${ }^{9}$.

\section{Challenges of using Digital Storytelling}

Digital storytelling has some challenges related to its use in museums. These challenges are varying as following:

- Cost of Resources: some sound effects and audio-visual materials (videos, animations...) are required in order to reach a certain level of produced content. This will in turn increase the cost of the production and the efforts of the museums' staff.

- Technologically Challenging: technology use has some software and hardware challenges depending on the specific applications, however it does not have major challenges since its appearance in the 1990s.

- Interdisciplinary: the decision of using digital storytelling in museums is a hard decision because many aspects should be considered in order to achieve the balance between many factors.

\section{Focus on exhibition vs. focus on media:}

designing digital stories have to consider museums' content in a way which highlights the exhibition space and exhibits without monopolizing visitors' attention to screens only. The using of digital media requires triangular relation between media, visitors and space. The main point here is finding a way to deepen the experience of the visitors putting into consideration the other two factors.

\section{Rich Information Space vs. Economy:}

choosing the valuable information and its amount is important for the audience who prefer to receive little information with great experience in an attractive way. So, telling stories from a specific point of view is more effective according to Jone Lambert who considered economy as one of the seven elements of successful storytelling. Immersive Plot vs. Interactivity: creating motivations for visitors is essential while giving the visitors the space to interact with the characters of the story. Cutting stories into small plots might badly affect visitors' experience.

\section{Fluency vs. Mobility:}

The mobility which appeared due to the existence of mobile applications challenges the fluency of the plot. The museums' structures force complex temporal and spatial restrictions. It also raises an important question regarding how to maintain describing the physical objects in the presence of fictional places and characters. Furthermore, mobility is a technical challenge on its own because localization technologies are still not mature enough to offer accuracy of less than 2-3 meters. This coverage

9 "Digital Storytelling and Cultural Heritage: Stakes and Opportunities," Athena Plus Access to Cultural Heritage Networks for Europeana, last modified Dec., 2015.http://www.athenaplus.eu/index.php?en/207/digital-storytelling-and-cultural-heritage 
is still not satisfactory to cover exhibition spaces with the objects closely situated to one another.

\section{Informative Role vs. Attractiveness of the Story:}

saving the balance between protecting the authenticity, credibility and authoritative knowledge of the museums' objects and building an attractive and entertaining story for different individuals and groups is not an easy task. Credibility and believability of the stories are linked together. Credibility means the accuracy of the presented information while, believability is a desired feature for the characters and environment of the story, and is not necessarily linked with perfect realism ${ }^{10}$.

\section{EMOTIVE Tips for the Good Plot}

- The different ways of making the plot have to be interesting. One worthy example for an interesting plot is Freytag Pyramid. The main character of this plot is trying to achieve her goal and overcome some obstacles after reaching the deepest point of depression.

- The story should be interactive. Creating dialogues between the characters themselves or the characters and users make the story more interactive.

- Interaction or the impression of interaction like asking the visitors some rhetorical questions can create an engaging story.

- Remind the visitors with the goals and objectives of the plot because they might forget it by the interaction with the surrounding spaces or visitors. Plots should be clear by avoiding the subtle cues and complicated conditions.

- Stories are most commonly about social conflicts.

- The story becomes more complex by providing frequent choices, so choices must be limited to keep the story short and interesting ${ }^{11}$.

\section{Conclusions}

Stories can connect people at an emotional level because they are a natural and spontaneous part of our upbringing, regardless of our cultural background. Also, stories and the practice of storytelling are part of any culture. Connecting creative storytelling with the destination development is a powerful approach which leads to social development and sustainable value creation. It also brings pride to people, and empowers them to contribute as much as they can. The history of storytelling started very early in museums in 1930 and continued its development until it witnessed the multimedia digital storytelling.

This fast development of storytelling was essential due to its great importance for people's social development. Storytelling has the power of improving listening skills, developing literacy Rate and offering learning without teaching opportunities. After collecting the data and forming the story, choosing the mediums is vital. The choice of the medium depends on some factors like the kind of the story, where and for whom it is going to be presented. To conclude, despite the fact that storytelling has some difficulties and challenges in particular cases, it has the upper hand concerning its advantages in delivering the information, engaging the audience and improving some social skills.

\footnotetext{
${ }^{10}$ Yannis Ioannidis et al., "One Object many Stories: Introducing ict in museums and collections through digital storytelling, " Marseille, France: IEEE, Feb., $20,2013,421-424$.

11"Conceptual Framework and Guide on Storytelling for Cultural Heritage," EMOTIVE, accessed Nov. 10 , 2017 T7xObXAhVBXhoKHfn3DhsQFghHMAU\&url=htt\%3A\%2F\%2Fwww.emotiveproject.eu\%2Fabout. php \&usg=AOvVaw3dT5TsvF92xnT 8 x 5 B K J r d 6
} 


\section{Bibliography}

Athena Plus Access to Cultural Heritage Networks for Europeana, "Digital Storytelling and Cultural Heritage: Stakes and Opportunities." Last modified Dec., 2015. http://www.athenaplus.eu/index.php?en/207/digital-storytellingand-cultural-heritage

Bernard Robin, "The educational uses of digital storytelling." In Society for Information Technology \& Teacher Education International Conference, (Orlando, Florida, USA: Association for the Advancement of Computing in Education (AACE), Retrieved January 17, 2019) 709-716. Available from: https://www.learntechlib.org/p/22129/ proceedings_22129.pdf

EMOTIVE. “Conceptual Framework and Guide on Storytelling for Cultural Heritage.” Accessed Nov. 10, 2017.

Fehlhammer, WolfPeter and Fuessl Wilhelm. "The Deutsches Museum: Idea, Realization, and Objectives.”Journal of the Technology and Culture 41, no. 3 (2000): 517-520. https://muse.jhu.edu/article/33555/summary

Fort Museum, Archaeological Survey of India. Report of Telling Storieswith Museum Objects-Reflection on Interpretation. Chennai: Fort St. George printer. http://network.icom.museum/fileadmin/user_upload/minisites/cidoc/ ConferencePapers/2015/CIDOC_Paper_K._Moortheeswari.pdf

Ioannidis Yannis et al., "One Object many Stories: Introducing ict in museums and collections through digitalstorytelling." Marseille, France: IEEE, Feb., 20, 2014. 421-424. https://iecexplore.iece.org/abstract/document/6743772/ references\#references

Killick, Steve, and Maria Boffey, Building relationships through storytelling. England: Fostering Network Wales press, 2012. https://www.thefosteringnetwork.org.uk/sites/www.fostering.net/files/content/buildingrelationships-through-storytelling-31-10-12.pdf

Paolo Paolini and Nicoletta Di Blas. Storytelling for cultural heritage. Switzerland: In Innovative technologies in urban mapping, 2014) https://link.springer.com/chapter/10.1007/978-3-319-03798-1_4

T7xObXAhVBXhoKHfn3DhsQFghHMAU\&url=http\%3A\%2F\%2Fwww.emotiveproject.eu\%2Fabout.

php\&usg=AOvVaw3dT5TsvF92xnT8x5BKJrd6

Trinkoff, Hayley. "Storytelling in Art Museums." Master's diss., Seton Hall University, 2015. http://scholarship.shu. edu $/$ cgi $/$ viewcontent.cgi?article $=3126 \&$ context $=$ dissertations 